\title{
Adaptive resistance to aminoglycoside antibiotics in Pseudomonas aeruginosa
}

\author{
LINDA B. GILLELAND, H. E. GILLELAND, JULIE A. GIBSON* and F. R. CHAMPLIN*
}

Department of Microbiology and Immunology, Louisiana State University Medical Center, School of Medicine in Shreveport, PO Box 33932, Shreveport, LA, 71130, and "Department of Biological Sciences, Mississippi State University, Mississippi State, MS, 39762, USA

\begin{abstract}
Summary. Aminoglycoside-resistant variants of Pseudomonas aeruginosa strain PAO1 were readily selected by culturing the organism in medium containing increasing concentrations of gentamicin, tobramycin or amikacin until the strains were growing in a concentration of drug 128 -fold greater than the minimal inhibitory concentration for the sensitive parent strain. These resistant strains exhibited characteristics previously associated with the impermeability type of resistance mechanism, i.e., they grew more slowly than the parent strain, the resistance was unstable in the absence of the antibiotic, and adaptation to one of the antibiotics conferred crossresistance to other aminoglycosides. The adapted strains grew, with minimal morphological alterations, in concentrations of the various aminoglycosides that normally produced cell envelope damage, misshapen and filamentous cell formation, and cell lysis in the sensitive strain. Neither protein $\mathrm{H} 1$ nor phospholipid alterations appear to play a significant role in adaptive resistance to aminoglycoside antibiotics in this model system. The acquisition of adaptive resistance to the aminoglycoside antibiotics did not confer resistance to polymyxin $\mathbf{B}$, another cationic antibiotic which is thought to share binding sites within the outer membrane with the aminoglycosides.
\end{abstract}

\section{Introduction}

Resistance to the cationic polymyxin and aminoglycoside antibiotics remains an incompletely understood phenomenon. When grown in the presence of one of these antibiotics, a population of gram-negative enteric rods or pseudomonads may exhibit increased resistance to the antibiotic through an unstable "impermeability mechanism". This resistance is readily lost when the strain is grown in the absence of the antibiotic. We have previously studied adaptive resistance to polymyxin $\mathrm{B}$ in a model system with Pseudomonas aeruginosa (Gilleland and Murray, 1976). The adaptation to increased polymyxin resistance involves both ultrastructural (Gilleland and Murray, 1976) and various chemical (Gilleland and Lyle, 1979; Conrad and Gilleland, 1981; Champlin et al., 1983) alterations of the outer membrane (OM) resulting in the prevention of polymyxin reaching the still sensitive cytoplasmic membrane (Gilleland and Farley, 1982). The chemical alterations comprised various

Received 20 July 1988; revised version accepted 20 Oct. 1988. lipid alterations, including a decrease in the phospholipid content in the readily extractable lipid (REL) with a reduction in phosphatidylethanolamine (PE) and phosphatidylglycerol (PG) content (Conrad and Gilleland, 1981), accompanied by the appearance of a large amount of free fatty acids (Champlin et al., 1983). We (Conrad and Gilleland, 1981; Champlin et al., 1983; Gilleland et al., 1984; Gilleland, 1988) and others (Kubesch et al., 1987) have proposed that changes in both the lipopolysaccharide (LPS) and the phospholipid composition of the OM might reduce the number of binding sites for polymyxin and render the OM more resistant to polymyxin. Kubesch et al. (1987) identified that PG, the major anionic phospholipid in the cell envelope, plays a critical role for the action of polymyxin on bacterial membranes.

The aminoglycoside antibiotics are a much more clinically important group of cationic antibiotics than are the polymyxins. It has been proposed (Hancock, 1981, 1986; Abdel-Sayed et al., 1982; Eagon, 1984; Taber et al., 1987) that the aminoglycoside antibiotics penetrate through the OM via a self-promoted pathway mediated by binding to 
cation-binding sites within the OM. Both the polymyxins and the aminoglycosides are thought to bind to the same sites within the OM, and Hancock and co-workers (Nicas and Hancock, 1980, 1983; Hancock, 1981; Hancock et al., 1981) have proposed that induction of OM-protein $\mathrm{Hl}$ in $P$. aeruginos a confers resistance to both the polymyxins and the aminoglycosides by protecting the binding site on LPS from attack. However, the role of the $\mathrm{H} 1$ protein in conferring resistance to these antibiotics has been disputed (Gilleland and Conrad, 1982; Said et al., 1987). Various investigators (Pechey and James, 1974; Dimitracopoulos et al., 1979; Al-Asadi et al., 1981; Gerber and Craig, 1982; Gerber et al., 1982; Bayer et al., 1987) have reported the isolation of aminoglycoside-resistant strains that exhibit the impermeability mechanism of resistance. This mechanism of resistance to the aminoglycoside antibiotics has been associated with alterations in LPS (Bryan et al., 1984; Galbraith et al., 1984; Clark et al., 1986). In this study we examined strains of $P$. aeruginosa made adaptively resistant to gentamicin, tobramycin and amikacin for the presence of alterations in their content of OM proteins and cell-envelope phospholipids. In particular, we examined whether the PG content of these aminoglycoside-resistant strains was reduced in a similar manner to the polymyxinresistant strains.

\section{Materials and methods}

\section{Bacterial strains}

The aminoglycoside-resistant strains were all selected from the PAOl parent strain of P. aeruginosa, which was susceptible to MICs of gentamicin $1 \mathrm{mg} / \mathrm{L}$, tobramycin $0.5 \mathrm{mg} / \mathrm{L}$, and amikacin $4 \mathrm{mg} / \mathrm{L}$. A resistant variant to each aminoglycoside was selected by stepwise growth of strain PAO1 in the presence of increasing concentrations of antibiotic until the strain was growing in the presence of an antibiotic concentration 128-fold greater than the MIC for the parent PAOl strain. Thus, the gentamicinresistant strain (PAO1-Gen ${ }^{r}$ ) was obtained by adding $3 \mathrm{ml}$ of a logarithmic-phase culture of strain PAO1 in basal medium (BM) after adjusting the absorbance at $660 \mathrm{~nm}\left(\mathrm{~A}_{660}\right)$ to $0 \cdot 3$, corresponding to a cell count of $(5-$ $7.5) \times 10^{8} \mathrm{cfu} / \mathrm{ml}$, to $50 \mathrm{ml}$ of $\mathrm{BM}$ containing gentamicin $1 \mathrm{mg} / \mathrm{L}$ in a $125-\mathrm{ml}$ Erlenmeyer flask. After aerobic incubation at $30^{\circ} \mathrm{C}$ for $36 \mathrm{~h}$, this culture was diluted with $\mathrm{BM}$ to give an $\mathrm{A}_{660}$ of 0.3 , and $3 \mathrm{ml}$ was added to $50 \mathrm{ml}$ of $\mathrm{BM}$ containing gentamicin $2 \mathrm{mg} / \mathrm{L}$, followed by incubation of the flask at $30^{\circ} \mathrm{C}$ with shaking for $24 \mathrm{~h}$. This stepwise transfer into media containing two-fold increases in the concentration of gentamicin was continued until the organism was growing in a gentamicin concentration of $128 \mathrm{mg} / \mathrm{L}$. A loopful of culture from this flask was streaked on basal medium agar plates containing gentamicin $100 \mathrm{mg} / \mathrm{L}$, and an isolated colony was picked as the PAO1-Gen ${ }^{\mathrm{r}}$ strain. Similar adaptation procedures were used to obtain a tobramycin-resistant $\left(\mathrm{PAO}-\mathrm{Tob}^{\mathrm{r}}\right)$ and an amikacin-resistant (PAOl-Ami $\left.{ }^{\mathrm{r}}\right)$ strain able to grow in the presence of tobramycin $64 \mathrm{mg} / \mathrm{L}$ and amikacin $512 \mathrm{mg} / \mathrm{L}$ respectively.

\section{Growth media}

The PAOl strain was grown in a basal medium (BM) previously described as "basal medium 2" (Gilleland $e t$ al., 1974). This medium contained the following ingredients adjusted to $\mathrm{pH} 7.0: 0.03 \mathrm{M}$ glucose, $0.04 \mathrm{M} \mathrm{K}_{2} \mathrm{HPO}_{4}$, $0.022 \mathrm{M} \mathrm{KH}_{2} \mathrm{PO} 4,0.007 \mathrm{M}\left(\mathrm{NH}_{4}\right)_{2} \mathrm{SO}_{4}$, and $0.0005 \mathrm{M}$ $\mathrm{MgSO}_{4}$. The aminoglycoside-resistant strains were grown in BM containing gentamicin $100 \mathrm{mg} / \mathrm{L}$ for the PAO1$\mathrm{Gen}^{\mathrm{r}}$ strain, tobramycin $50 \mathrm{mg} / \mathrm{L}$ for the PAO1-Tob ${ }^{\mathrm{r}}$ strain, and amikacin $500 \mathrm{mg} / \mathrm{L}$ for the PAOl-Amir strain.

Cells for experiments were routinely grown at $30^{\circ} \mathrm{C}$ with aeration either in 125 -ml Erlenmeyer flasks containing $50 \mathrm{ml}$ of the appropriate medium or in 4-L Erlenmeyer flasks containing $2 \mathrm{~L}$ of medium.

\section{Determination of growth characteristics}

The growth characteristics for the PAOl strain and each of the three aminoglycoside-resistant strains were determined as follows. A 300 -ml side arm Erlenmeyer flask containing $20 \mathrm{ml}$ of BM plus the appropriate concentration of antibiotic was seeded from a logarithmic-phase starter culture to give an initial $A_{660}$ reading of 0.05 . The flasks were incubated at $30^{\circ} \mathrm{C}$ in a shaking water bath, and $A_{660}$ readings were taken at 1-2 $h$ intervals for $22 \mathrm{~h}$.

\section{Reversion of the aminoglycoside-resistant strains}

The ability of the PAO1-Gen ${ }^{\mathrm{r}}$, PAO1-Tob ${ }^{\mathrm{r}}$, and PAO1$\mathrm{Ami}^{\mathrm{r}}$ strains to revert to antibiotic susceptibility was assessed as follows. An inoculum of $0.5 \mathrm{ml}$ from a logarithmic culture growing in BM plus the appropriate antibiotic was used to inoculate a flask containing $50 \mathrm{ml}$ of $\mathrm{BM}$ without antibiotic for each strain. After incubation for $24 \mathrm{~h}$ at $30^{\circ} \mathrm{C}$ with shaking, $0.5 \mathrm{ml}$ was transferred to a second flask containing $50 \mathrm{ml}$ of BM without antibiotic and again incubated for $24 \mathrm{~h}$. These cells were used as inocula for MIC determinations (see below) and for cultures for cell envelope preparation. Data regarding reverted strains were obtained after growth of the strains for three successive transfers in antibiotic-free BM.

\section{Determination of minimal inhibitory concentrations of various antibiotics}

The MICs of various antibiotics were determined for the parent PAO1 strain, the three aminoglycosideresistant strains, and the three reverted strains as described by Gilleland and Farley (1982). The antibiotics 
tested included gentamicin sulphate from Schering Corp. (Kenilworth, NY), tobramycin sulphate (Nebcin) and streptomycin sulphate from Eli Lilly and Co. (Indianapolis, IN), amikacin from Bristol Laboratories (Syracuse, NY), and polymyxin B sulphate from Pfizer, Inc. (New York, NY).

\section{Electronmicroscopy of thin-sectioned preparations}

All strains were prepared and fixed with glutaraldehyde and $\mathrm{OsO} 4$, with poststaining of sections with uranyl acetate and lead citrate as described by Gilleland and Farley (1982).

\section{Analysis of cell-envelope proteins}

Cell envelopes were prepared from the PAO1 strain, the three aminoglycoside-resistant strains, and the reverted strains according to the procedure of Stinnett $e t$ al. (1973). Proteins were extracted from these cell envelopes and analysed by slab sodium dodecylsulphatepolyacrylamide gel electrophoresis as described by Gilleland and Lyle (1979).

\section{Lipid analysis}

The PAOl strain grown in BM and the three aminoglycoside-resistant strains grown in BM containing the appropriate antibiotic were used for lipid analysis. The readily extractable lipid (REL) fraction was obtained by chloroform: methanol $(2: 1)$ extraction of freeze-dried whole cells by the Conrad et al. (1979) modification of the method of Folch et al. (1957). The cellular dry weight percentage of RELs was measured gravimetrically (Conrad and Gilleland, 1981). The phosphate content of REL fractions was measured by the method of Ames and Dubin (1960). Lipids in the REL fractions were resolved by thin-layer chromatography on Adsorbosil-Plus 1 silica gel plates (Alltech Associates, Inc., Deerfield, IL). Chromatograms were developed to a distance of $10 \mathrm{~cm}$ in chloroform:methanol:acetic acid:water (85:15:10:3.5) (Hanna et al., 1984), air dried, and developed to a distance of $14 \mathrm{~cm}$ in hexane:diethyl ether (4:1). Separated lipids were visualised by spraying with potassium dichromate-saturated $50 \% \mathrm{H}_{2} \mathrm{SO}_{4}$ and charring at $150^{\circ} \mathrm{C}$ for $30 \mathrm{~min}$. RELs were tentatively identified by cochromatography with authentic reference lipids (Sigma Chemical Co., St Louis, MO) which included diphosphatidylglycerol (DPG), phosphatidylethanolamine (PE), phosphatidylglycerol (PG), palmitic acid, and oleic acid. The ratios of individual lipids were determined by scanning densitometry as previously described (Conrad and Gilleland, 1981).

\section{Statistical analysis}

The statistical significance of the results of the lipid analysis was determined by Student's $t$ test on the means, with (two-tailed) p-values of 0.05 and lower considered significant.

\section{Results}

\section{Characteristics of the aminoglycoside-resistant strains}

Strains resistant to each of the three aminoglycoside antibiotics were readily obtained but they grew more slowly than did the parent strain (PAO1) and attained a lower cell density in cultures. In the absence of antibiotic, the sensitive PAO1 strain grew in BM with a doubling time of $2.6 \mathrm{~h}$ to reach a final $A_{660}$ reading of 1.2 within an incubation period of $16 \mathrm{~h}$. The PAOl-Gen ${ }^{\mathrm{r}}$ strain grew in BM plus gentamicin $100 \mathrm{mg} / \mathrm{L}$ with a doubling time of $3 \mathrm{~h}$ to reach a final $A_{660}$ reading of 1.0 within $20 \mathrm{~h}$. The PAO1-Tob ${ }^{r}$ strain grew in BM containing tobramycin $50 \mathrm{mg} / \mathrm{L}$ with a doubling time of $3.9 \mathrm{~h}$ to reach a final $\mathrm{A}_{660}$ reading of 0.75 within $18 \mathrm{~h}$. The PAO1-Amir strain grew in BM plus amikacin $500 \mathrm{mg} / \mathrm{L}$ with a doubling time of $5 \cdot 3 \mathrm{~h}$ to reach a final $\mathrm{A}_{660}$ reading of 0.68 within $22 \mathrm{~h}$.

Adaptive resistance from growth in the presence of one of the aminoglycoside antibiotics conferred cross-resistance to the other three aminoglycosides tested (table I). The adaptive resistance was unstable; growth of the resistant strains for three transfers in BM without antibiotic resulted in all three strains reverting to antibiotic susceptibility (table I).

\section{Electronmicroscopy of thin-sectioned preparations}

The unadapted PAO1 strain could not survive and grow, even with prolonged incubation, in BM containing gentamicin $100 \mathrm{mg} / \mathrm{L}$, tobramycin $50 \mathrm{mg} / \mathrm{L}$, or amikacin $500 \mathrm{mg} / \mathrm{L}$. Exposure of PAO1 cells to gentamicin $100 \mathrm{mg} / \mathrm{L}$ resulted in a progression of cellular damage as shown in fig. 1. After exposure to gentamicin for $30 \mathrm{~min}$ (fig. 1A), numerous small blebs of the OM were seen, with an occasional larger ballooning out of the membrane. After exposure for $1 \mathrm{~h}$ (fig. 1B), more filamentous cells were found, and the cells also became more misshapen. The cell population became even more misshapen and filamentous after exposure for $2 \mathrm{~h}$ (fig. 1C), and lysis of cells began to occur. By $4 \mathrm{~h}$, most of the cells were in various stages of lysis (fig. 1D). Exposure to tobramycin $50 \mathrm{mg} / \mathrm{L}$ had a similar effect on the PAOl cells; blebbing of the $O M$ and misshapen cells were prominent findings (fig. 2A). Lesions and infoldings of the cytoplasmic membrane were more extensive in cells exposed to tobramycin (fig. 2C) than in those exposed to gentamicin. Extensive cell lysis occurred in tobramycin-exposed cells by $4 \mathrm{~h}$, with 
Table I. MIC's of aminoglycoside antibiotics and polymyxin B for the $P$. aeruginosa strains

\begin{tabular}{lccccc}
\hline & \multicolumn{5}{c}{ Antibiotic MIC (mg/L) } \\
\cline { 2 - 6 } Strain & Gentamicin & Tobramycin & Amikacin & Streptomycin & Polymyxin B \\
\hline PAO1 & 1 & $0 \cdot 5$ & 4 & 32 & 8 \\
PAO1-Gen & 128 & $64 \cdot 0$ & 512 & 512 & 16 \\
PAO1-Tob & 128 & $64 \cdot 0$ & 256 & 512 & 8 \\
PAO1-Ami & 64 & $32 \cdot 0$ & 512 & 512 & 8 \\
PAO1-Gen & 4 & $2 \cdot 0$ & 16 & 64 & ND \\
PAO1-Toverted & 1 & $2 \cdot 0$ & 8 & 32 & ND \\
PAO1-Ami-reverted & 2 & $2 \cdot 0$ & 16 & 64 & ND \\
\hline
\end{tabular}

$\mathrm{ND}=$ not determined

separation of the OM from the cytoplasmic membrane (fig. 2D) frequently preceding lysis. Amikacin produced effects in the PAO1 cells (fig. 2B) similar to those produced by the other two aminoglycosides. However, the cells were not as misshapen nor was the cytoplasm as darkly staining within the first hour as with gentamicin or tobramycin.

The resistant strains were capable of survival and growth in the presence of the concentrations of aminoglycoside antibiotics which produced extensive cell damage and lysis in the PAO1 strain. These strains did not show the ballooning and separation of the OM layer, the formation of grossly misshapen and filamentous cells, the cytoplasmic membrane infoldings, and the cell lysis produced in the PAO1 strain by these concentrations of antibiotics. These resistant strains appeared remarkably healthy. However, in comparison to the PAO1 strain grown in BM, growth in the presence of the antibiotic did result in slightly misshapen cells.

\section{Analysis of OM proteins}

In all the resistant strains there was a reduction in a number of outer membrane protein bands in comparison to the sensitive PAO1 strain and the reverted strains (fig. 3). All three resistant strains demonstrated a reduced content of several of the bands in the 73-69-Kda range. Most obviously associated with loss and regain in all three strains was the 69-Kda band, which was reduced in all three strains and regained to wild-type concentrations in all three reverted strains. Protein F (porin, $36 \mathrm{Kda}$ ) was reduced in all three strains, as was protein $\mathrm{H} 1(21 \mathrm{Kda})$. No band was increased in the resistant strains relative to the $\mathrm{PAO} 1$ and reverted strains.

\section{Lipid analysis}

Separation of REL fraction lipids by thin-layer chromatography revealed no apparent alteration of lipid composition in any of the aminoglycosideresistant strains compared with the parental PAO1 strain. Quantitation of individual lipids by densitometry (table II) confirmed that there were no consistently significant differences between the content of the various lipids in the PAO1 strain and in the three resistant strains. The only statistically significant differences between the PAO1 strain and the resistant strains were an increase in free fatty acids in the PAO1-Amir strain and an increase in DPG in the PAO1-Tob strain (table II). Although the PG content was slightly reduced in all three resistant strains (reduction of $7.4 \%$ in PAO1-Gen ${ }^{\mathrm{r}}, 12 \%$ in PAOl-Tob ${ }^{\mathrm{r}}$, and $10.7 \%$ in PAO1-Amir) compared to the PAOl strain, the magnitude of the reduction did not approach the $74-90 \%$ reduction in $\mathrm{PG}$ content previously reported (Conrad and Gilleland, 1981; Champlin et $a l ., 1983$ ) for the polymyxin-resistant $P$. aeruginosa strains. Neither the cell percentage of REL nor the phospholipid proportion of the REL (as measured by determining $\mu \mathrm{mol}$ of phosphorus per mg of REL) differed significantly between the PAO1 and the resistant strains (table II). Thus, the adaptation to aminoglycoside resistance did not result in any significant alteration in lipid content in the REL.

\section{Discussion}

In our in-vitro model of resistance to aminoglycoside antibiotics, resistant strains were readily obtained for each of the three antibiotics used. All three resistant strains exhibited characteristics associated with the impermeability mechanism of resistance. These characteristics included slower 

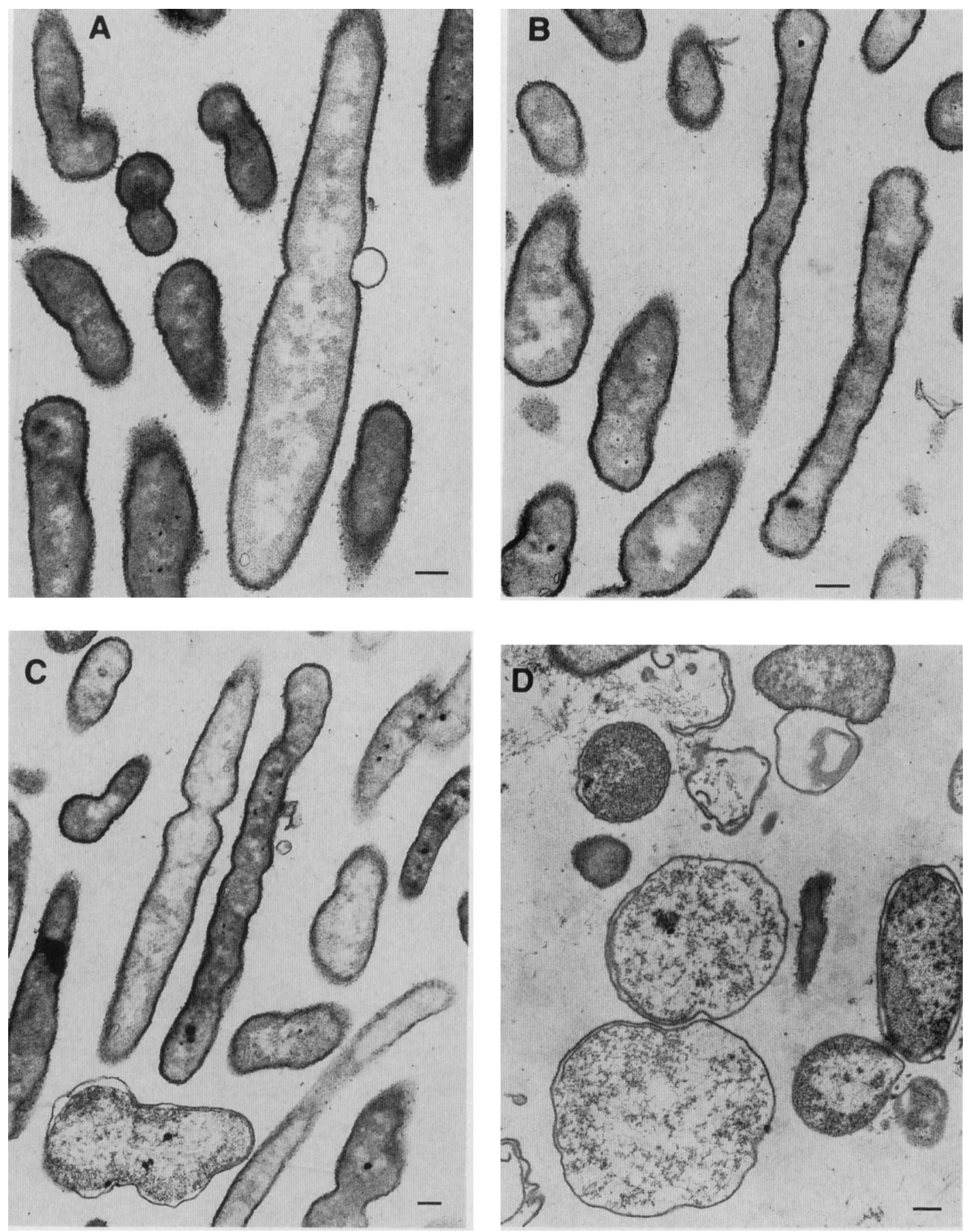

Fig. 1. P. aeruginosa strain PAOl after exposure to gentamicin $100 \mathrm{mg} / \mathrm{L}$. (A) Cells fixed after exposure for $30 \mathrm{~min}$; note blebbing of the OM and misshapen cells. (B) Cells fixed after exposure for $1 \mathrm{~h}$; note the cells have become more misshapen and filamentous. (C) Cells fixed after exposure for $2 \mathrm{~h}$; cell lysis has become more frequent. (D) Cells fixed after exposure for $4 \mathrm{~h}$; extensive cell lysis has occurred. Bars $=200 \mathrm{~nm}$. 

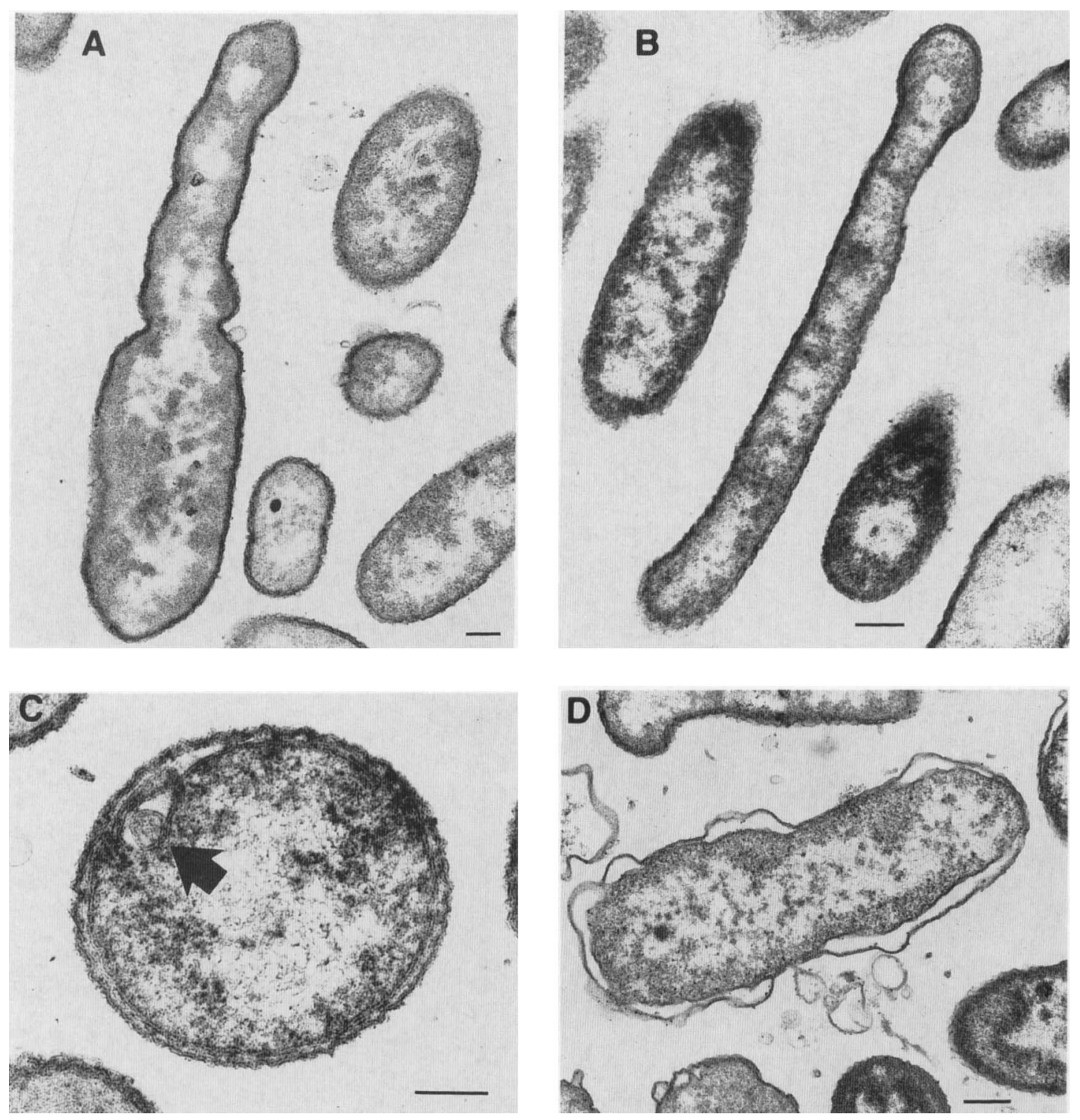

Fig. 2. $P$. aeruginosa strain PAOl after exposure to aminoglycoside antibiotics. (A) Cells fixed after exposure to tobramycin 50 $\mathrm{mg} / \mathrm{L}$ for $1 \mathrm{~h}$; note the OM blebs and misshapen cell. (B) Cells fixed after exposure to amikacin $500 \mathrm{mg} / \mathrm{L}$ for $1 \mathrm{~h}$; note the filamentous cell with a large $\mathrm{OM}$ bleb. (C) Cell fixed after exposure to tobramycin $50 \mathrm{mg} / \mathrm{L}$ for $2 \mathrm{~h}$; note the infolding of the cytoplasmic membrane (arrow) - such lesions in the cytoplasmic membrane were frequently encountered in tobramycin-treated cells. (D) Cell fixed after exposure to tobramycin $50 \mathrm{mg} / \mathrm{L}$ for $4 \mathrm{~h}$; note the separation of the OM from the cytoplasmic membrane, which was commonly seen before cell lysis. Bar $=200 \mathrm{~nm}$.

growth than the parent strain (Gilleland and Murray, 1976; Eagon, 1984) and cross-resistance to all four aminoglycosides tested (Pechey and James, 1974; Al-Asadi et al., 1981; Shannon and Phillips, 1982). This resistance was unstable and strains readily reverted to susceptibility during several transfers in the absence of antibiotic (Pechey and James, 1974; Gilleland and Murray, 1976; Dimitra- copoulos et al., 1979; Bayer et al., 1987). Furthermore, we were unable to detect aminoglycosideinactivating enzymes in any of the three resistant strains by techniques that did allow demonstration of such an enzyme from a positive control strain (data not shown). Therefore, we conclude that our resistant strains were resistant by an impermeability mechanism. 


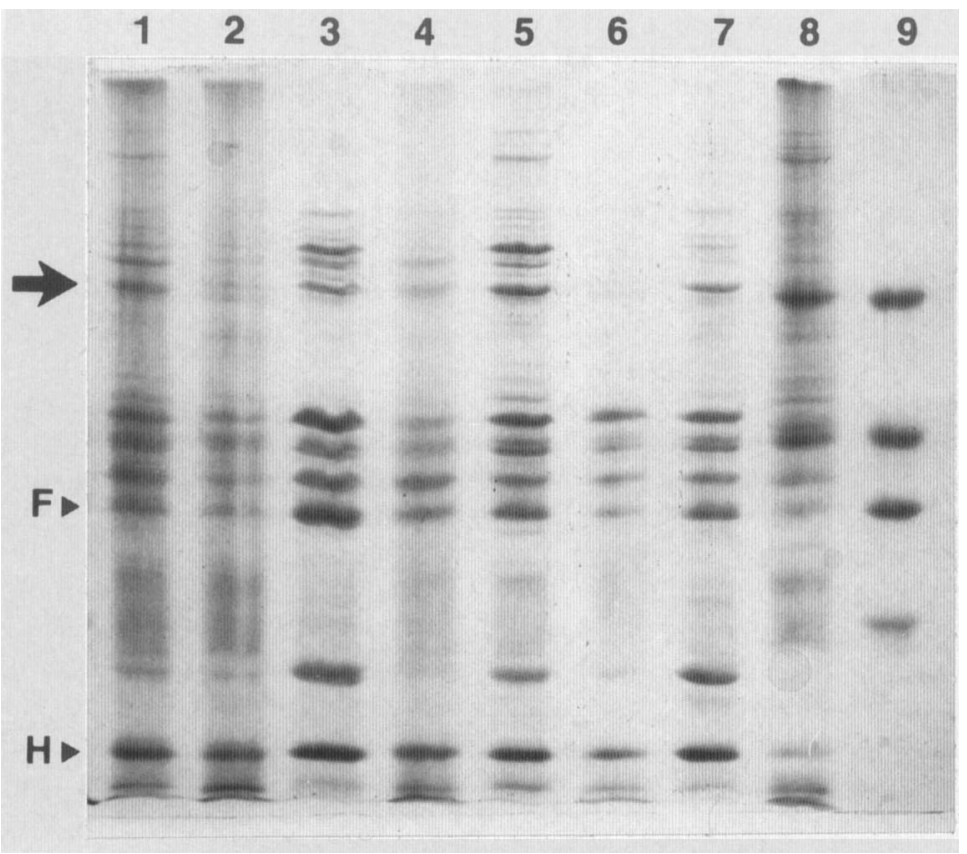

Fig. 3. SDS-PAGE of cell envelope proteins of the various $P$. aeruginosa strains. Lane 1 , the susceptible PAO1 strain; lane 2 , the gentamicin-resistant PAO1-Gen ${ }^{\mathrm{r}}$ strain; lane 3, PAO1-Gen ${ }^{\mathrm{r}}$ reverted to susceptibility; lane 4, the tobramycin-resistant PAO1-Tob ${ }^{\mathrm{r}}$ strain; lane 5, PAO1-Tob reverted to susceptibility; lane 6, the amikacin-resistant PAO1-Ami ${ }^{\mathrm{r}}$ strain ; lane 7, PAO1-Ami ${ }^{\mathrm{r}}$ reverted to susceptibility; lane 8, the polymyxin B-resistant isolate A strain; lane 9, molecular weight standards of $66,44,36$ and $24 \mathrm{Kda}$. On the left, the location of a $69-\mathrm{Kda}$ band (arrow), protein F (labelled F), and protein H1 (labelled H) is indicated. Note that the resistant strains (lanes $2,4,6$, and 8 ) do not have an increased content of protein H1. Reductions in various protein bands, including protein $\mathrm{F}$ and those in the 69-73-Kda range, are evident.

The precise role played by the impermeability type of resistance to aminoglycoside antibiotics in clinical medicine remains undetermined. Since this type of resistance is generally unstable in the absence of the antibiotic, strains possessing impermeable-type resistance in the presence of the antibiotic in the patient would lose the resistance upon routine culturing for isolation in the clinical laboratory and would appear to be susceptible to the antibiotic upon routine testing of antibiotic susceptibilities in the clinical laboratory (Gerber et al., 1982). Emergence of such aminoglycoside-

Table II. Analysis of REL fractions from the P. aeruginosa strains

REL Component

Mean percentage composition $\dagger(\mathrm{SD})$

\begin{tabular}{|c|c|c|c|c|c|c|c|}
\hline Strain & $\begin{array}{l}\text { Total un- } \\
\text { known }\end{array}$ & FFA & DPG & PE & PG & $\begin{array}{l}\text { REL, mean per- } \\
\text { centage of dry } \\
\text { cell weight } \ddagger \text { (SD) }\end{array}$ & $\begin{array}{l}\text { Mean Pi content } \\
\text { in } \mu \mathrm{mol} / \mathrm{mg} \text { of } \\
\text { REL } \S(\mathrm{SD})\end{array}$ \\
\hline PAOl & $12 \cdot 24(2 \cdot 40)$ & $1 \cdot 10(0 \cdot 49)$ & $14 \cdot 78(2 \cdot 33)$ & $49 \cdot 76(3 \cdot 13)$ & $22 \cdot 14(2 \cdot 02)$ & $11.75(0.65)$ & $1 \cdot 18(0 \cdot 15)$ \\
\hline PAO1-Gen ${ }^{5}$ & $11 \cdot 26(2 \cdot 28)$ & $1 \cdot 30(0.40)$ & $16 \cdot 77(3 \cdot 56)$ & $50.69(3.37)$ & $20.51(2.81)$ & $11 \cdot 94(0.48)$ & $1.23(0.13)$ \\
\hline PAOl-Tob & $10 \cdot 44(2 \cdot 91)$ & $1.42(0.51)$ & $19 \cdot 11(3.55)^{*}$ & $50.69(3.68)$ & $19.49(2.80)$ & $12 \cdot 42(0.23)$ & $1 \cdot 18(0 \cdot 14)$ \\
\hline PAOl-Amir & $12 \cdot 22(2 \cdot 21)$ & $1.89(0.40)^{*}$ & $13 \cdot 74(2 \cdot 14)$ & $52 \cdot 38(3 \cdot 45)$ & $19 \cdot 78(2 \cdot 47)$ & $11.61(0.04)$ & $1 \cdot 13(0 \cdot 13)$ \\
\hline
\end{tabular}

† Seven to eight determinations were used for each value.

$\ddagger$ Three determinations were used for each value.

$\S$ Eight to ten determinations were used for each value.

* Value is statistically significantly different from the equivalent value for the PAOl strain as determined by Student's $t$ test on the means, employing the two-tailed $t$ table. 
resistant strains has been shown to occur not only in vitro but also in animal models (Gerber et al., 1982; Bayer et al., 1987) and in human patients (Bryan et al., 1976; Mawer and Greenwood, 1977; Bryan et al., 1984; Olson et al., 1985). The emergence of resistance occurs more frequently with $P$. aeruginosa than with the Enterobacteriaceae (Gerber and Craig, 1982; Nilsson et al., 1987) and is thought to play a role in the difficulty encountered in treating infections caused by $P$. aeruginosa with aminoglycoside therapy (Olson et al., 1985). Clinical strains displaying the impermeability type of resistance have low-level aminoglycoside resistance, which some authors (Gerber and Craig, 1982; Gerber et al., 1982) attribute to the antibiotic selection of resistant subpopulations already existing in the generally susceptible population. However, it appears that a pre-existing resistant subpopulation is not necessary for the emergence of adaptive resistance, because newly resistant subpopulations also appear (Olson et al., 1985). Indeed, in-vitro models of resistance development to high-level resistance, after several steps, show strains growing in antibiotic concentrations which would normally kill a population of the original parent strain. We believe that the emergence of more resistant subpopulations, which are not found in the initial cell population, plays a role in in-vitro models and in-vivo clinical situations.

In this study the three resistant strains were grown routinely in the presence of aminoglycosides in concentrations corresponding to $100 \times \mathrm{MIC}$ for the parent PAO1 strain, with only quite minor aberrations in cell morphology. These minor ultrastructural abnormalities in cell shape may indicate that exclusion of the antibiotic by the impermeability mechanism is not absolute but that only small quantities are able to penetrate. However, the resistant cells are protected against extensive ultrastructural alterations (misshapen and filamentous cells, figs. 1, 2A, and 2B) which these antibiotic concentrations produce in the PAO1 strain. Others (Nishino and Nakazawa, 1975; Martin and Beveridge, 1986) have reported that aminoglycoside antibiotics cause breaks or holes in the cell envelope layers of susceptible cells, as well as causing blebbing or outpouching of the OM (Iida and Koike, 1974; Nishino and Nakazawa, 1975; Martin and Beveridge, 1986). We found similar effects in the PAO1 strain treated with each of the aminoglycoside antibiotics. In addition to the $\mathrm{OM}$ and cytoplasmic membrane alterations noted, the antibiotics all produced alterations in cell morphology, with extensive cell lysis occurring after exposure for 2-4 h. Marked morphological changes with a loss of cell shape and the occurrence of rounded cells leading to lytic death of $P$. aeruginosa upon exposure to aminoglycoside antibiotics was described previously by Nishino and Nakazawa (1975) and by Lorian and Atkinson (1986). We believe these morphological changes and cell lysis result from indirect effects on cell metabolic processes consequent upon inhibition of protein synthesis by the binding of the aminoglycoside to the $30 \mathrm{~S}$ ribosomal subunit. The resistant strains described here would be protected from these effects by exclusion of the antibiotic from entry into the cytoplasm in sufficient quantity to disrupt cell metabolism.

In this study we examined the role played by two different cell-envelope components in the adaptive impermeability type of resistance to aminoglycoside antibiotics. An increase in OM protein $\mathrm{H} 1$ has been proposed (Nicas and Hancock, 1980, 1983; Hancock, 1981; Hancock et al., 1981) to mediate resistance to aminoglycosides, polymyxin $\mathrm{B}$, and EDTA. However, since no increase in OM protein $\mathrm{H} 1$ was evident in any of the three resistant strains (fig. 3), we could find no evidence that this protein plays any role in adaptive resistance to aminoglycosides in our model system. Several of the other OM proteins were reduced in all three adapted strains. However, since the aminoglycoside antibiotics are believed not to use OM porins for entry but to cross the OM by a self-promoted pathway involving binding to cationic binding sites within the OM (Abdel-Sayed et al., 1982; Hancock, 1986), the possible significance of the reduced content of these OM proteins is uncertain. However, the reduction in several bands in the $73-69-\mathrm{Kda}$ range is noteworthy since Morris and Brown (1988) recently reported that subinhibitory concentrations of the aminoglycosides inhibit the production of iron-chelating siderophores. Certain of these high molecular weight OM proteins may be ironregulated proteins that are reduced in the adapted strains. The second cell envelope component we examined for a possible role in adaptive aminoglycoside resistance was the composition of the REL fraction. Alterations in the phospholipid composition, particularly the loss of PG (Kubesch et al., 1987), have been reported to be associated with adaptive resistance to another cationic antibiotic polymyxin B (Conrad and Gilleland, 1981 ; Champlin et al., 1982). However, no consistent alteration in REL lipid content could be demonstrated in the three aminoglycoside-resistant strains (table II), and we conclude that lipid alterations such as those reported for adaptive resistance to polymyxin $\mathbf{B}$ play no significant role in this resistance to the 
aminoglycosides. LPS alterations have been reported in strains exhibiting the impermeability type of resistance to aminoglycoside antibiotics in in-vitro models (Dimitracopoulos et al., 1979; Galbraith et al., 1984) and clinical isolates (Bryan et al., 1984; Clarke et al., 1986). Alterations in LPS thus remain the most likely basis for adaptive resistance to the aminoglycosides.

It has been proposed (Brown, 1975; Hancock, 1981; Nicas and Hancock, 1980, 1983) that EDTA and the cationic aminoglycoside and polymyxin antibiotics all act at cationic binding sites on the LPS so that various conditions (growth in $\mathrm{Mg}^{2+}$. deficient medium, increase in OM protein $\mathrm{H1}$, etc.) confer resistance to all three agents. This implies that these agents share common binding require-

\section{REFERENCES}

Abdel-Sayed S, Gonzalez M, Eagon R G 1982 The role of the outer membrane of Pseudomonas aeruginosa in the uptake of aminoglycoside antibiotics. Journal of Antimicrobial Chemotherapy 10: 173-183.

Al-Asadi M J S, Towner K, Greenwood D 1981 Acquired cross resistance to aminoglycosides in gentamicin-sensitive and gentamicin-resistant strains of enterobacteria. Journal of Medical Microbiology 14: 171-183.

Ames B N, Dubin D T 1960 The role of polyamines in the neutralization of bacteriophage deoxyribonucleic acid. Journal of Biological Chemistry 235: 769-775.

Bayer A S, Norman D C, Kim K S 1987 Characterization of impermeability variants of Pseudomonas aeruginosa isolated during unsuccessful therapy of experimental endocarditis. Antimicrobial Agents and Chemotherapy 31: 70-75.

Brown M R W 1975 The role of the cell envelope in resistance. In: Brown M R W (ed) Resistance of Pseudomonas aeruginosa. John Wiley and Sons, London, pp 71-107.

Bryan LE, Haraphognse R, von den Elzen H M 1976 Gentamicin resistance in clinical isolates of Pseudomonas aeruginosa associated with diminished gentamicin accumulation and no detectable-enzymatic modification. Journal of Antibiotics 29: 743-753.

Bryan L E, O'Hara K, Wong S 1984 Lipopolysaccharide changes in impermeability-type aminoglycoside resistance in Pseudomonas aeruginosa. Antimicrobial Agents and Chemotherapy 26: $250-255$.

Champlin F R, Gilleland H E, Conrad R S 1983 Conversion of phospholipids to free fatty acids in response to acquisition of polymyxin resistance in Pseudomonas aeruginosa. Antimicrobial Agents and Chemotherapy 24: 5-9.

Clark R B, Hu D H, Janda J M, Hostetter M K 1986 Increased susceptibility of gentamicin-resistant Pseudomonas aeruginosa to human sera. Current Microbiology 13: 159-162.

Conrad R S, Gilleland H E 1981 Lipid alterations in cell envelopes of polymyxin-resistant Pseudomonas aeruginosa isolates. Journal of Bacteriology 148: 487-497.

Conrad R S, Wulf R G, Clay D L 1979 Effects of carbon sources on antibiotic resistance in Pseudomonas aeruginosa. Antimicrobial Agents and Chemotherapy 15: 59-66.

Dimitracopoulos G, Intzes C, Papavassiliou J 1979 Characteristics of Pseudomonas aeruginosa in relation to laboratory- ments within the OM of $P$. aeruginosa. However, since resistance to polymyxin B (MIC raised from $6 \mathrm{mg} / \mathrm{L}$ for the PAO1 strain to $5000 \mathrm{mg} / \mathrm{L}$ for isolate A) results in only low-level (2-fold increase in MIC) resistance to aminoglycoside antibiotics (Gilleland and Farley, 1982) and an 128-fold increase in MIC for aminoglycoside antibiotics results in no significant increase in resistance to polymyxin B (this study), we conclude that these two groups of cationic antibiotics must have, within the OM, certain binding requirements that are unique to each antibiotic group. The observation that lipid alterations appear to play an important role in resistance to polymyxin B but appear to play no significant role in adaptive resistance to aminoglycosides is consistent with this suggestion.

induced resistance to gentamicin. Journal of Clinical Pathology 32: 723-727.

Eagon R G 1984 The resistance characteristics of Pseudomonas. Developments in Industrial Microbiology 25: 337-348.

Folch J, Lees M, Stanley G H S 1957 A simple method for the isolation and purification of total lipids from animal tissues. Journal of Biological Chemistry 226: 497-509.

Galbraith L et al. 1984 Structural alterations in the envelope of a gentamicin-resistant rough mutant of Pseudomonas aeruginosa. Annales de Microbiologie (Institut Pasteur) 135B: 121-136.

Gerber A U, Craig W A 1982 Aminoglycoside-selected subpopulations of Pseudomonas aeruginosa, characterization and virulence in normal and leukopenic mice. Journal of Laboratory and Clinical Medicine 100: 671-681.

Gerber A U, Vastola A P, Brandel J, Craig W A 1982 Selection of aminoglycoside-resistant variants of Pseudomonas aeruginosa in an in vivo model. Journal of Infectious Diseases 146: 691-697.

Gilleland H E 1988 Adaptive alterations in the outer membrane of gram-negative bacteria during human infection. Canadian Journal of Microbiology 34: 499-502.

Gilleland H E, Champlin F R, Conrad R S 1984 Chemical alterations in cell envelopes of Pseudomonas aeruginosa upon exposure to polymyxin: a possible mechanism to explain adaptive resistance to polymyxin. Canadian Journal of Microbiology 30: 869-873.

Gilleland H E, Conrad R S 1982 Chemical alterations in cell envelopes of polymyxin-resistant mutants of Pseudomonas aeruginosa grown in the absence or presence of polymyxin. Antimicrobial Agents and Chemotherapy 22: 1012-1016.

Gilleland H E, Farley L B 1982 Adaptive resistance to polymyxin in Pseudomonas aeruginosa due to an outer membrane impermeability mechanism. Canadian Journal of Microbi$\operatorname{ology} 28$ : 830-840.

Gilleland H E, Lyle R D 1979 Chemical alterations in cell envelopes of polymyxin-resistant Pseudomonas aeruginosa isolates. Journal of Bacteriology 138 : 839-845.

Gilleland H E, Murray R G E 1976 Ultrastructural study of polymyxin-resistant isolates of Pseudomonas aeruginosa. Journal of Bacteriology 125 : 267-281.

Gilleland H E, Stinnett J D, Eagon R G 1974 Ultrastructural and chemical alteration of the cell envelopes of Pseudomonas aeruginosa, associated with resistance to ethylenediamine- 
tetraacetate resulting from growth in a $\mathrm{Mg}^{2+}$-deficient medium. Journal of Bacteriology 117: 302-311.

Hancock R E W 1981 Aminoglycoside uptake and mode of action-with special reference to streptomycin and gentamicin. I. Antagonists and mutants. Journal of Antimicrobial Chemotherapy 8: 249-276.

Hancock R E W 1986 Intrinsic antibiotic resistance of Pseudomonas aeruginosa. Journal of Antimicrobial Chemotherapy 18: 653-656.

Hancock R E W, Raffle V J, Nicas T I 1981 Involvement of the outer membrane in gentamicin and streptomycin uptake and killing in Pseudomonas aeruginosa. Antimicrobial Agents and Chemotherapy 19: 777-785.

Hanna K, Bengis-Garber C, Kushner D J, Kogut M, Kates M 1984 The effect of salt concentration on the phospholipid and fatty acid composition of the moderate halophile Vibrio costicola. Canadian Journal of Microbiology 30: 669-675.

Iida K, Koike M 1974 Cell wall alterations of gram-negative bacteria by aminoglycoside antibiotics. Antimicrobial Agents and Chemotherapy 5: 95-97.

Kubesch P, Boggs J, Luciano L, Maass G, Tümmler B 1987 Interaction of polymyxin B nonapeptide with anionic phospholipids. Biochemistry 26: 2139-2149.

Lorian V, Atkinson B A 1986 Amikacin-induced alterations in the structure of gram-negative bacilli. Diagnostic Microbiology and Infectious Disease 5: 93-97.

Martin N L, Beveridge T J 1986 Gentamicin interaction with Pseudomonas aeruginosa cell envelope. Antimicrobial Agents and Chemotherapy 29: 1079-1087.

Mawer S L, Greenwood D 1977 Aminoglycoside resistance emerging during therapy. Lancet $1: 749-750$.

Morris G, Brown M R W 1988 Novel modes of action of aminoglycoside antibiotics against $P$ seudomonas aeruginosa. Lancet 1: 1359-1360.

Nicas T I, Hancock R E W 1980 Outer membrane protein H1 of Pseudomonas aeruginosa: involvement in adaptive and mutational resistance to ethylenediaminetetraacetate, polymyxin B and gentamicin. Journal of Bacteriology 143: 872-878.

Nicas T I, Hancock R E W 1983 Alteration of susceptibility to EDTA, polymyxin B and gentamicin in Pseudomonas aeruginosa by divalent cation regulation of outer membrane protein H1. Journal of General Microbiology 129 : 509-517.

Nilsson L, Sören L, Radberg G 1987 Frequencies of variants resistant to different aminoglycosides in Pseudomonas aeruginosa. Journal of Antimicrobial Chemotherapy 20: 255259.

Nishino T, Nakazawa S 1975 Morphological alteration of Pseudomonas aeruginosa by aminoglycoside antibiotics. Journal of Electron Microscopy 24 : 73-86.

Olson B, Weinstein R A, Nathan C, Chamberlin W, Kabins S A 1985 Occult aminoglycoside resistance in Pseudomonas aeruginosa : epidemiology and implications for therapy and control. Journal of Infectious Diseases 152: 769-774.

Pechey D T, James A M 1974 Surface properties of cells of gentamicin-sensitive and gentamicin-resistant strains of Pseudomonas aeruginosa. Microbios 10A Suppl $41: 111-126$.

Said A A, Livermore D M, Williams R J 1987 Expression of H1 outer-membrane protein of Pseudomonas aeruginosa in relation to sensitivity to EDTA and polymyxin B. Journal of Medical Microbiology 24: 267-274.

Shannon K, Phillips I 1982 Mechanisms of resistance to aminoglycosides in clinical isolates. Journal of Antimicrobial Chemotherapy 9: 91-102.

Stinnett J D, Gilleland H E, Eagon R G 1973 Proteins released from cell envelopes of Pseudomonas aeruginosa on exposure to ethylenediaminetetraacetate: comparison with dimethylformamide-extractable proteins. Journal of Bacteriology 114: 399-407.

Taber H W, Mueller J P, Miller P F, Arrow A S 1987 Bacterial uptake of aminoglycoside antibiotics. Microbiological Reviews 51 : 439-457. 